\title{
Peau d'orange
}

National Cancer Institute

\section{Source}

National Cancer Institute. Peau d'orange. NCI Thesaurus. Code C7740.

Swelling and dimpling of the surface of the skin, which is typically associated with carcinoma of the breast. 